\title{
Tearing it up: Addressing the septum during endovascular repair of chronic distal aortic dissections
}

\author{
Jennifer Chung, MD, MSc, and Maral Ouzounian, MD, PhD
}

\footnotetext{
From the Division of Cardiovascular Surgery, Peter Munk Cardiac Centre, Toronto General Hospital, University of Toronto, Toronto, Ontario, Canada.

Disclosures: Authors have nothing to disclose with regard to commercial support.

Received for publication July 17, 2018; accepted for publication July 21, 2018; available ahead of print Sept 6 , 2018.

Address for reprints: Maral Ouzounian, MD, PhD, Peter Munk Cardiac Centre, 200 Elizabeth St, 4N-464, Toronto, ON M5G 2C4 Canada (E-mail: Maral.ouzounian@uhn.ca).

J Thorac Cardiovasc Surg 2019;157:99-100

$0022-5223 / \$ 36.00$

Copyright (c) 2018 by The American Association for Thoracic Surgery

https://doi.org/10.1016/j.jtcvs.2018.07.056
}

Aneurysmal degeneration of chronic distal aortic dissections (CDADs), whether after type A or type B aortic dissections, is a challenging entity for endovascular repair. Unlike in nondissected descending thoracic aortic aneurysms, for which endovascular repair is standard of care in most scenarios, the role of endovascular repair for CDADs is still developing. The thickened, sometimes complex septum encountered in CDADs may interfere with endograft expansion, including in landing zones, resulting in significant endoleaks and continued pressurization of the aneurysmal sac. Branches may also be dependent on false-lumen perfusion, requiring advanced techniques to avoid organ ischemia.

Numerous techniques have been explored to overcome challenges associated with the distal landing zone in the setting of CDAD. Intraluminal fenestration of the septum as an open technique was described to facilitate distal seal. ${ }^{1}$ Endovascular techniques involving balloon angioplasty, with or without adjunct reentry devices, were then adapted to achieve this same result. The cheese-wire technique achieves longitudinal disruption of the septum by downward traction of a wire straddling the true and false lumens. ${ }^{2}$ Alternatively, the knickerbocker technique achieves distal seal after stent-graft deployment by balloon rupture of the septum from within the graft. ${ }^{3}$ The perfused distal false lumen may also be closed with coils, slurries, or plugs. 4 Finally, distal extension with snorkels or branched and fenestrated devices has also been reported when the optimal sealing zone extends further distally across the visceral segment or into the iliac bifurcation. ${ }^{6}$ The large variety of available techniques highlights the fact that not one technique is ideal, that endovascular repair of CDAD is rapidly evolving and remains challenging, and that there are limitations and potential dangers for each technique.

In this issue of the Journal, Sharafuddin and colleagues ${ }^{7}$ described their approach to optimizing the distal landing zone in 16 patients being treated in the setting of a CDAD. They used a combination of balloon dilation of native or needle-induced fenestrations, and wire-cutting

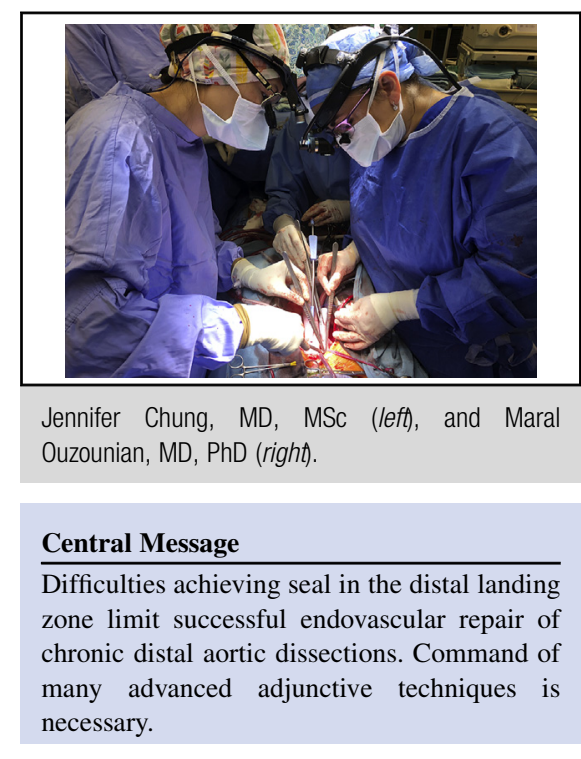

See Article page 88 .

techniques, including an interesting variation they termed "squeegee wire fenestration." Balloon molding of the endografts was used to expand the stent grafts sufficiently into this optimized landing zone.

Sharafuddin and colleagues ${ }^{7}$ are to be commended on good results with such a challenging pathology. They used a thoughtful and evolving approach to the septum, with a plethora of adjunctive techniques. Even after distal landing zone optimization, they still required fenestrated grafts, one snorkel, iliac branch grafts, and several Amplatzer devices (St Jude Medical Inc, St Paul, Minn) to achieve distal seal. Despite this aggressive approach, of the 16 patients in the series, 1 died intraoperatively, 2 became unavailable for follow-up, and, after a mean follow-up of 15 months, 3 of the remaining patients still returned with a type IB endoleak. This highlights the fact that complex endovascular repairs demand frequent and vigilant follow-up imaging surveillance. The high risk of reintervention, even with careful management of the septum, should be discussed, particularly if younger patients are being considered for treatment.

The alternative is, of course, open distal aortic repair. Although invasive, the safety of open repair continues to improve, and it is versatile and durable. Continued innovation in endovascular techniques is important, but the role for open surgery in the treatment of this pathology unquestionably persists. After many years and a wide array of adjuncts, 
the limitations of endovascular repair for CDAD are far from resolved. We wonder whether a truly "disruptive" technology beyond available devices will be necessary if minimally invasive surgery is ultimately to supplant open repair of aneurysmal chronic aortic dissection.

\section{References}

1. Roselli EE, Sepulveda E, Pujara AC, Idrees J, Nowicki E. Distal landing zone open fenestration facilitates endovascular elephant trunk completion and false lumen thrombosis. Ann Thorac Surg. 2011;92:2078-84.

2. Tashiro J, Baqai A, Goldstein LJ, Salsamendi JT, Taubman M, Rey J. "Cheese wire" fenestration of a chronic aortic dissection flap for endovascular repair of a contained aneurysm rupture. J Vasc Surg. 2014;60:497-9.
3. Kölbel T, Carpenter SW, Lohrenz C, Tsilimparis N, Larena-Avellaneda A, Debus ES. Addressing persistent false lumen flow in chronic aortic dissection: the knickerbocker technique. J Endovasc Ther. 2014;21:117-22.

4. Norberto EM, Gutiérrez VM, Taylor J, Vaquero C. Coil embolization of persistent false lumen after stent graft repair of type B aortic dissection. J Vasc Surg. 2011; 54:201-4.

5. Kölbel T, Lohrenz C, Kieback A, Diener H, Debus ES, LarenaAvellaneda A. Distal false lumen occlusion in aortic dissection with a homemade extra-large vascular plug: the candy-plug technique. J Endovasc Ther. 2013;20:484-9.

6. Sobocinski J, Spear R, Tyrrell MR, Maurel B, Martin Gonzalez T, Hertault A, et al. Chronic dissection-indications for treatment with branched and fenestrated stent-grafts. J Cardiovasc Surg (Torino). 2014;55:505-17.

7. Sharafuddin MJ, Bhama JK, Bashir M, Aboul-Hosn M, Man JH, Sharp AJ. Distal landing zone optimization before endovascular repair of aortic dissection. J Thorac Cardiovasc Surg. 2019;157:88-98. 